\title{
Reticulocyte Hemoglobin Equivalent: Diagnostic Performance in Assessment of Iron Deficiency in Patients with Hypothyroidism
}

\author{
Wardah Aslam $\left(\mathbb{D},{ }^{1}\right.$ Maryam Habib $\mathbb{D}^{2},{ }^{2}$ Saeeda Aziz, ${ }^{1}$ and Madiha Habib $\mathbb{D}^{3}$ \\ ${ }^{1}$ Nuclear Medicine Oncology and Radiotherapy Institute, Islamabad, Pakistan \\ ${ }^{2}$ Shifa College of Medicine (STMU), Islamabad, Pakistan \\ ${ }^{3}$ University of Malaya, Kuala Lumpur, Malaysia \\ Correspondence should be addressed to Maryam Habib; maryam.scm@stmu.edu.pk
}

Received 15 July 2021; Revised 24 October 2021; Accepted 29 October 2021; Published 12 November 2021

Academic Editor: Kalkidan Hassen

Copyright $\odot 2021$ Wardah Aslam et al. This is an open access article distributed under the Creative Commons Attribution License, which permits unrestricted use, distribution, and reproduction in any medium, provided the original work is properly cited.

\begin{abstract}
Introduction. Iron deficiency affects approximately $30 \%$ of the world population and is frequently encountered in hypothyroid patients. Early recognition and prompt treatment of iron deficiency in hypothyroid patients lead to a favorable outcome. The aim of this study is to prove the usefulness of reticulocyte hemoglobin equivalent (Ret-He) as a reliable and effective tool in diagnosis of iron deficiency in hypothyroid patients. Materials and Methods. 154 patients with hypothyroidism were included in the study. They were divided into 4 groups. Group 1 included 66 hypothyroid patients without iron deficiency. They were taken as controls. Group 2 included 66 hypothyroid patients with iron deficiency anemia (IDA). Group 3 included 12 hypothyroid patients with iron deficiency but without anemia (ID). Group 4 included 10 hypothyroid patients which had concomitant iron deficiency with anemia of chronic disorder (ACDC). Ret-He was measured by analyzing blood samples on System XN 350. Thyroid profile, serum ferritin, and biochemical data were measured by an automated analyzer. Statistical analysis was performed by using SPSS 23 . Results. Ret-He was significantly lower with $(p<0.001)$ in group 2 (hypothyroid patients with IDA), group 3 (hypothyroid patients with ID), and in group 4 (hypothyroid patients with ACDC) as compared to controls in group 1 (hypothyroid patients without iron deficiency). After ROC analysis area under the curve (AUC) of Ret-He for hypothyroid patients with IDA was 0.96 at cutoff $28.5 \mathrm{pg}$ with sensitivity of $93 \%$ and specificity of $90 \%$. AUC of Ret-He in the hypothyroid group with ACDC was 0.99 at cutoff $30.8 \mathrm{pg}$ with sensitivity of $90 \%$ and specificity of $90 \%$. AUC of Ret-He in hypothyroid patients with ID was 0.97 at cutoff $31.7 \mathrm{pg}$ with sensitivity of $91 \%$ and specificity of $70 \%$. Conclusion. Ret-He is a reliable, rapid, and cost-effective tool for diagnosing iron deficiency in hypothyroid patients.
\end{abstract}

\section{Introduction}

Anemia is a global health problem affecting about one-third of population worldwide [1]. Iron deficiency anemia is one of the most common causes of anemia. Approximately half of all the cases of anemia throughout the world are due to iron deficiency. It affects all age groups, particularly children and women of childbearing age. It remains as one of the leading causes of morbidity and mortality. Iron deficiency may develop before development of frank anemia, and it may exist in combination with other anemias. Worldwide iron deficiency remains undiagnosed in most of the patients admitted with different illnesses in hospitals, especially before the development of frank iron deficiency anemia
[2-5]. Iron deficiency is a state in which body is unable to meet its requirements due to unavailability of iron. It may be in the form of absolute iron deficiency, in which there is insufficient iron in body stores for adequately matching the demand by erythropoiesis in the bone marrow, whereas functional iron deficiency is a state in which the body contains sufficient or more than sufficient iron, but the iron cannot be mobilized from the stores in the reticuloendothelial system to meet the demand for the erythropoiesis [6]. The other important cause of anemia related to iron metabolism is immune activation causing anemia of chronic disorder [7]. Iron deficiency is commonly seen in hypothyroid patients. This can occur due to a variety of reasons. These reasons include decreased iron absorption from gut 
because of decreased enzymes and acids, decreased levels of erythropoietin found in hypothyroid patients, and in females with menorrhagia due to hypothyroidism. Many hypothyroid patients are not screened for iron deficiency due to financial constraints of ordering multiple tests and cumbersome ways of diagnosing it particularly in the undeveloped countries. Timely recognition and treatment of iron deficiency in hypothyroid patients can lead to better outcomes with greater and improved response to treatment with thyroxine. Iron deficiency can manifest itself as frank iron deficiency anemia, latent iron deficiency, and iron deficiency in combination with anemia of chronic disorder in hypothyroid patients [8-13]. Diagnosis and investigation of iron deficiency requires many parameters which include serum ferritin, serum iron, total iron binding capacity, serum transferrin, and transferrin saturation [14]. Reticulocytes are immature RBCs that are released from the bone marrow. New parameters have been defined for reticulocyte analysis which measure hemoglobin content of reticulocytes and stages of their development. These parameters include immature reticulocyte fraction (IRF), reticulocyte hemoglobin equivalent (Ret-He), and reticulocyte hemoglobin content (CHr). Ret-He and $\mathrm{CHr}$ give information about mean content of hemoglobin in developing reticulocytes and are thus affected earlier in diminished hemoglobin production in iron deficiency and iron deficiency anemia as compared to other parameters. Ret-He can be used as an effective tool to detect iron deficiency in different states and anemias. It can be done on the same sample taken for complete blood count in EDTA anticoagulant. Instead of performing many biochemical tests for detecting iron deficient states, it can be used solely for the identification of iron deficiency. Performing many tests leads not only to increased cost for patients, but some of the tests used for detecting iron deficiency have a limited value in presence of infection and malignancy [15]. Ret-He can be used as a single, rapid, and cost-effective test for determining iron status [16-18]. Many studies have been conducted in the past establishing effectiveness of Ret-He in diagnosing iron deficiency in patients suffering from different disorders. To our knowledge, this is one of the first studies aiming to determine the effectiveness of Ret-He in evaluating iron deficiency with and without anemia in hypothyroid patients. This will lead to timely recognition of iron status in hypothyroid patients resulting in better and effective management and improved outcome in these patients.

\section{Materials and Methods}

This prospective study was conducted at Nuclear Medicine Oncology and Radiology Institute, Islamabad, over a period of 2 years from February 2019 till November 2020.The study protocol was approved according to Ethics Review Board of Nuclear Medicine Oncology and Radiotherapy Institute, Islamabad, on $29^{\text {th }}$ January 2019 with ethical reference no. NORI-2(10)/88. One hundred and fifty-four adult patients with hypothyroidism (based on clinical diagnosis and laboratory confirmation) presenting to the outpatient department were randomly enrolled in the study. Hypothyroid patients with hemoglobinopathies and nutritional deficiency anemia other than iron deficiency were excluded from the study. As the study was conducted based on thyroid profile, $\mathrm{CBC}$ reports, and relevant biochemical investigations of patients with no direct contact with the patient, informed consent was not required. Waiver for informed consent was provided by the Ethical Committee and Review Board of Nuclear Medicine Oncology and Radiotherapy Institute, Islamabad. Hypothyroid patients were divided into four groups. Group 1 included 66 hypothyroid patients without iron deficiency. They were taken as controls. Group 2 included 66 hypothyroid patients with iron deficiency anemia (IDA). Group 3 included 12 hypothyroid patients with iron deficiency but without anemia (ID). Group 4 included 10 hypothyroid patients who had concomitant iron deficiency with anemia of chronic disorder (ACDC). The inclusion criteria for hypothyroidism, IDA (males and females), ID (males and females), ACDC (males and females), and control (males and females) are mentioned.

Hypothyroidism: serum TSH $>4.0 \mathrm{mIU} / \mathrm{L}, \quad \mathrm{T} 3$ $<3.1 \mathrm{pmol} / \mathrm{L}$, and/or T4 $<12 \mathrm{pmol} / \mathrm{L}$.

IDA (female): $\mathrm{Hb}<7.45 \mathrm{mmol} / \mathrm{L}$, serum ferritin $<13 \mathrm{ug} /$ $\mathrm{L}$, TIBC $>46.36 \mathrm{umol} / \mathrm{L}$, serum iron $<11 \mathrm{umol} / \mathrm{L}$, and CRP $<5 \mathrm{mg} / \mathrm{L}$

IDA (male): $\mathrm{Hb}<8.7 \mathrm{mmol} / \mathrm{L}$, serum ferritin $<30 \mathrm{ug} / \mathrm{L}$, TIBC $>46.36 \mathrm{umol} / \mathrm{L}$, serum iron $<14 \mathrm{umol} / \mathrm{L}$, and CRP $<5 \mathrm{mg} / \mathrm{L}$

ID (female): $\mathrm{Hb}>7.45 \mathrm{mmol} / \mathrm{L}$, serum ferritin $<13 \mathrm{ug} /$ $\mathrm{L}$, serum TIBC $>46.36 \mathrm{umol} / \mathrm{L}$, serum iron $<11 \mathrm{umol} / \mathrm{L}$, and CRP $<5 \mathrm{mg} / \mathrm{L}$

ID (male): $\mathrm{Hb}>8.07 \mathrm{mmol} / \mathrm{L}$, serum ferritin $<30 \mathrm{ug} / \mathrm{L}$, serum $\mathrm{TIBC}>46.36 \mathrm{umol} / \mathrm{L}$, serum iron $<14 \mathrm{umol} / \mathrm{L}$, and $\mathrm{CRP}<5 \mathrm{mg} / \mathrm{L}$

ACDC (female): $\mathrm{Hb}<7.45 \mathrm{mmol} / \mathrm{L}$, serum TIBC $<46.36 \mathrm{umol} / \mathrm{L}$, serum iron $>11 \mathrm{umol} / \mathrm{L}$, serum ferritin $>13 \mathrm{ug} / \mathrm{L}$, and CRP $>5 \mathrm{mg} / \mathrm{L}$.

ACDC (male): $\mathrm{Hb}<8.07 \mathrm{mmol} / \mathrm{L}$, serum TIBC $<46.36 \mathrm{umol} / \mathrm{L}$, serum iron $>11 \mathrm{umol} / \mathrm{L}$, serum ferritin $>30 \mathrm{ug} / \mathrm{L}$, and CRP $>5 \mathrm{mg} / \mathrm{L}$.

Control (male): $\mathrm{Hb}>8.07 \mathrm{mmol} / \mathrm{L}$, serum ferritin $>13 \mathrm{ug} / \mathrm{L}$ serum TSH $>4.2 \mathrm{mIU} / \mathrm{L}, \mathrm{T} 3<3.1 \mathrm{pmol} / \mathrm{L}$, and or $\mathrm{T} 4<12 \mathrm{pmol} / \mathrm{L}, \mathrm{CRP}<5 \mathrm{mg} / \mathrm{L}$.

Control (female): $\mathrm{Hb}>7.45 \mathrm{nmol} / \mathrm{L}$, serum ferritin $>13 \mathrm{ug} / \mathrm{L}$, serum TSH $>4.2 \mathrm{mIU} / \mathrm{L}, \mathrm{T} 3<3.1 \mathrm{pmol} / \mathrm{L}, \mathrm{T} 4$ $<12 \mathrm{pmol} / \mathrm{L}$, and CRP $<5 \mathrm{mg} / \mathrm{L}$.

Thyroid profile was performed on COBAS E602 by using electrochemiluminescence technology. Biochemical parameters were measured using ROCHE COBAS 60000 by using immunoassay (electrochemiluminescence method). CBC parameters including $\mathrm{Hb}, \mathrm{MCV}, \mathrm{RDWCV}, \mathrm{RDWSD}$, and RDWSD were measured by using Sysmex XN 350, which used the cyanide-free SLS method for measuring hemoglobin and the impedance method with hydrodynamic focusing for measuring $\mathrm{RBC}$ parameters. Reticulocyte 
hemoglobin equivalent was measured on the same sample by running Sysmex XN 350 on the retic mode by using the fluorescence flow cytometry method. All the data were analyzed by using SPSS Version 23. Descriptive analysis of the data was performed. Age and gender were statistically comparable between 4 groups. The Kolmogorov-Smirnov and Shapiro-Wilk test revealed no significant departure from normality for the variables. ROC curve was used to find area under curve (AUC) for Ret-He in IDA, ID, and ACDC in hypothyroid patients keeping serum ferritin and transferrin saturation levels $<20 \%$ as gold standard.

\section{Results}

In group 1 (hypothyroid patients without iron deficiency taken as control), there were 28 males and 38 females with age range of 28-64 years. In group 2 (hypothyroid patients with IDA), there were 22 males and 44 females with age range of 18-61 years. In group 3 (hypothyroid patients with ID), there were 7 males and 5 females with age range of 43-60 years. In group 4 (hypothyroid patients with ACDC), there were 4 males and 6 females with age range of 43-63 years. After ROC analysis area under curve (AUC) of Ret-He for detecting IDA in hypothyroid patients was 0.96 at cutoff $28.5 \mathrm{pg}$ with maximum specificity of $90 \%$ and sensitivity of 93\%. AUC of Ret-He in hypothyroid patients with ACDC was 0.99 at cutoff $30.8 \mathrm{pg}$ with sensitivity of $90 \%$ and specificity of $90 \%$. AUC of Ret-He for diagnosing ID in hypothyroid patients was 0.97 at cutoff $31.7 \mathrm{pg}$ with sensitivity of $91 \%$ and specificity of $70 \%$. ROC curves for IDA, ID, and ACDC in hypothyroid patients have been compared as shown in Figure 1.

Hypothyroid patients in IDA, ID, and ACDC groups had significantly lower values of Ret-He than controls $(p<0.001)$. Mean values of Ret-He, Hb, ferritin, TSH, T3, and T4 in hypothyroid patients with IDA, ACDC, ID, and control are given in Table 1.

\section{Discussion}

The prevalence of thyroid disorders is quite high in Pakistan, but most hypothyroid patients with iron deficiency are misdiagnosed. Ret-He has been employed for the identification of iron deficiency in patients with different diseases, but, to our knowledge, this is one of the first studies which has focused on determining the effectiveness of Ret-He in diagnosing iron deficiency in hypothyroid patients. The study shows that Ret-He can be used as an effective single marker of iron deficiency in hypothyroid patients in different states. It is cost-effective, easily measured, performed on the same sample taken for complete blood count, and can identify iron deficiency in different states $[19,20]$. We calculated Ret-He in 66 hypothyroid patients without iron deficiency taken as controls and 66 hypothyroid patients with IDA. Values of Ret-He were significantly lower in hypothyroid patients having IDA as compared to controls. Uçar et al. [21] conducted a study in which the value of Ret$\mathrm{He}$ was significantly lower in iron deficient groups as compared to control. Our study also showed the value of

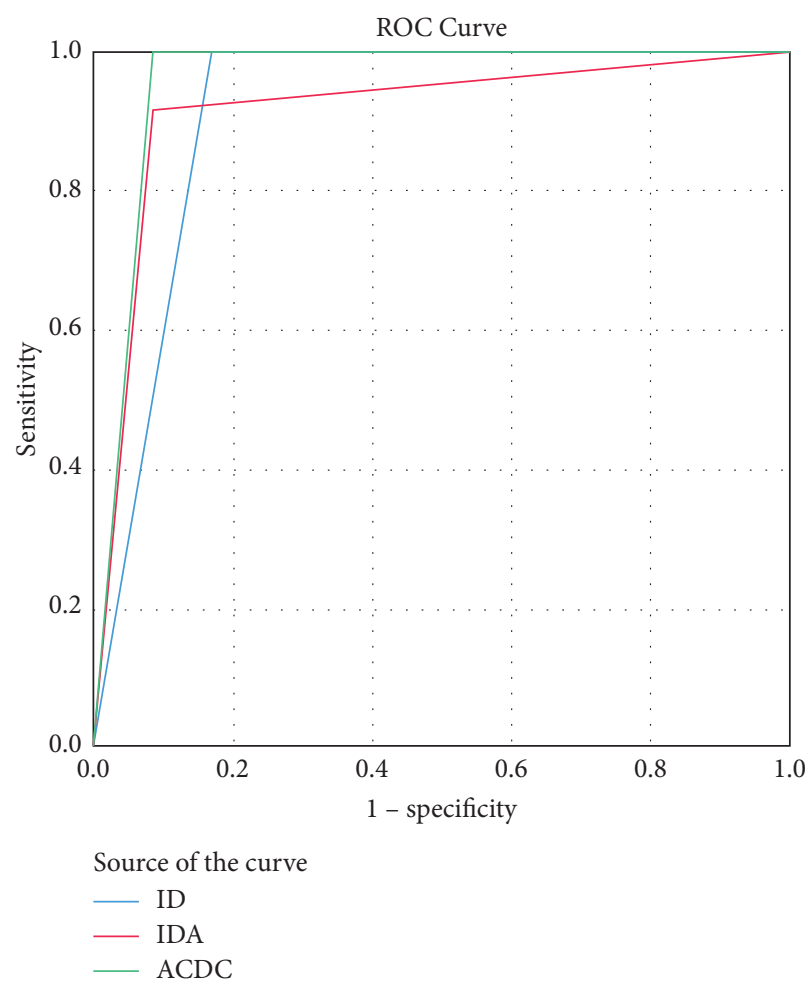

FIgure 1: Comparison of ROC curve for IDA, ID, and ACDC in hypothyroid patients.

Ret-He was significantly low in groups with iron deficiency in combination with anemia of chronic disorder and latent iron deficiency. A study was conducted by Wirawan et al. [22] on concordance between Ret-He and $\mathrm{CHr}$ in diagnosing iron deficiency in chronic kidney disease patients. They found Ret-He at cutoff $29.2 \mathrm{pg}$ had a sensitivity and specificity of $95.5 \%$ and $94 \%$ in assessing the target of iron supplementation in hemodialyzed patients. A study performed by Gelaw et al. [23] shows significance of Ret-He in diagnosing iron deficiency in IDA and functional iron deficiencies. We found at cutoff 28.5 pg Ret-He had a sensitivity of $93 \%$ and specificity of $90 \%$ in diagnosing IDA. Research performed by Chinudomwong et al. [24] had comparable results. Their study demonstrated that Ret-He at cutoff $30 \mathrm{pg}$ had $96 \%$ sensitivity and $97 \%$ specificity in diagnosing IDA. A study performed by Khan et al. [25] revealed Ret-He at cutoff $<27.6 \mathrm{pg}$ with sensitivity and specificity of $93.3 \%$ and $83.3 \%$ in diagnosing iron deficient states. Ret-He holds a special significance in anemia of chronic disease combined with iron deficiency as serum ferritin levels which are widely used in diagnosing iron deficiency that are altered due to chronic inflammation. We evaluated the role of Ret-He in identifying iron deficiency in combination with anemia of chronic disorder. Ret-He at cutoff $30.8 \mathrm{pg}$ had sensitivity of $90 \%$ and specificity of $90 \%$ for identifying iron deficiency coexisting with anemia of chronic disorder. In cases where iron deficiency was present before developments of frank anemia, Ret-He at cutoff $31.7 \mathrm{pg}$ had $91 \%$ sensitivity and $70 \%$ specificity. A study conducted by Singh et al. [26] evaluated the role of Ret-He in 
TABLE 1: Biochemical parameters and thyroid profile in hypothyroid patients with IDA, ACDC, ID, and control.

\begin{tabular}{lcccc}
\hline & $\begin{array}{c}\text { Hypothyroid patients } \\
\text { without iron deficiency } \\
\text { and anemia (control) } \\
n=66\end{array}$ & $\begin{array}{c}\text { Hypothyroid patients } \\
\text { with iron deficiency } \\
\text { and anemia (IDA) } \\
n=66\end{array}$ & $\begin{array}{c}\text { Hypothyroid patients } \\
\text { with iron deficiency } \\
\text { without anemia (ID) } \\
n=12\end{array}$ & $\begin{array}{c}\text { Hypothyroid patients } \\
\text { with anemia } \\
\text { and chonic disorder combined } \\
\text { with iron deficiency (ACDC) } \\
n=10\end{array}$ \\
\hline Ret-He (pg) & $33.0 \pm 2.1$ & $21.0 \pm 1.3$ & $28.2 \pm 0.2$ & $25 \pm 1.5$ \\
Hb (nmol/L) & $8.98 \pm 0.81$ & $6.19 \pm 0.1$ & $9.10 \pm 0.75$ & $6.37 \pm 0.2$ \\
Ferritin (ug/L) & $144 \pm 23.62$ & $10.1 \pm 2.0$ & $123 \pm 20.5$ & $260.46 \pm 55.75$ \\
TSH (mIU/L) & $34.71 \pm 0.15$ & $36.0 \pm 1.8$ & $39 \pm 2.1$ & $40 \pm 2.8$ \\
T3 (pmol/L) & $2.97 \pm 0.21$ & $1.98 \pm 0.13$ & $2.01 \pm 0.16$ & $2.89 \pm 0.22$ \\
T4 (pmol/L) & $11.01 \pm 0.32$ & $9.41 \pm 0.21$ & $9.785 \pm 0.23$ & $10.2 \pm 0.29$ \\
\hline
\end{tabular}

The data are expressed as mean \pm S.D.

rheumatologic patients. They found Ret-He of $<24 \mathrm{pg}$ in IDA, 24-26.5 pg highly sensitive and specific in iron deficiency combined with anemia of chronic disorder, and $>26.5 \mathrm{pg}$ in anemia of the chronic disease group. Toki et al. [18] conducted a study on 211 patients aged 14-91 years of age. They classified patients into four groups: IDA group, ID group, control group, and anemia without ID group. The median Ret-He values were 22.3 (15.1-35.6 pg), $29.7 \mathrm{pg}$ (19.2-34.9 pg), $34 \mathrm{pg}$ (25.9-38 pg), and $32.5 \mathrm{pg}$ (19.1-46.3 pg) in the IDA, ID, control, and anemia without ID. We had mean Ret-He of $21.35 \mathrm{pg}$ in IDA. Dalimunthe and Lubis [27] calculated receiver operating characteristic (ROC) curve for Ret-He in iron deficient patients which revealed area under the curve of $0.818(p<0.0001)$, which is slightly lower than our study. Our study showed area under curve of 0.93 . Their cutoff for diagnosing iron deficiency anemia was slightly higher than our results. They used $31.65 \mathrm{pg}$ as cutoff Ret-He with $81.5 \%$ sensitivity and $61.6 \%$ specificity as compared to our cutoff Ret-He at $28.5 \mathrm{pg}$.

4.1. Limitations of Study. Despite being an important study, which assesses the importance of Ret-He in diagnosing iron deficiency in different states in hypothyroid patients, this study has some limitations. The role of Ret-He in diagnosing iron deficiency in hypothyroid patients with different hemoglobinopathies needs to be investigated as the number of patients having hemoglobinopathies specifically thalassemia is quite high in our country. Additionally, the number of hypothyroid patients in the study having ID and ACDC, the parameters suggesting the efficacy of Ret-He in diagnosing these states in hypothyroid patients, is quite small, and larger studies need to be conducted for further establishing the effectiveness of Ret-He in diagnosing ID and ACDC in hypothyroid patients. A further longitudinal limitation of this study is that it lacks follow up of patients after starting iron therapy.

\section{Conclusion}

In conclusion, Ret-He is an effective, rapid, inexpensive, and reliable parameter with very high sensitivity and specificity for ruling out concomitant iron deficiency in hypothyroid patients.

\section{Abbreviations}

Ret-He: Reticulocyte hemoglobin equivalent

IDA: Iron deficiency anemia

ID: Latent iron deficiency

ACDC: Anemia of chronic disorder combined with iron deficiency.

\section{Data Availability}

The datasets generated and/or analyzed during the current study are not publicly available due to hospital policy on maintaining confidentiality and privacy of patient information but are available from the corresponding author upon request.

\section{Ethical Approval}

"The authors are accountable for all aspects of the work in ensuring that questions related to the accuracy or integrity of any part of the work are appropriately investigated and resolved." The study protocol was approved by the Ethics Committee and Institutional Review Board of Nuclear Medicine Oncology and Radiotherapy Institute Islamabad on $29^{\text {th }}$ January 2019 with ethical reference no. NORI-2(10)/ 88. Ethical approval by Research Training and Monitoring Cell (RTMC) of Nuclear Medicine, Oncology and Radiotherapy Institute, was granted with vide reference no. RTMC 4/1-150-2021/NORI-ERC-10/1, dated July 2021.

\section{Consent}

Informed consent is not applicable as all the data were collected from laboratory investigations performed, with no direct involvement of patients. Waiver for informed consent was provided by Ethics Committee and Review board of Nuclear Medicine Oncology and Radiotherapy Institute, Islamabad.

\section{Disclosure}

Conference proceedings: Aslam W, Habib M, Mahmood H, Liaquat A, Aziz S, Fatima S, and Habib M. Reticulocyte Hemoglobin Equivalent: A Study on Comparison and Effectiveness in Assessment of Iron Deficiency: ISLH 2019 
Abstracts, International Journal of Laboratory Hematology. Abstract Proceedings of the 32nd Annual Meeting of the International Society for Laboratory Hematology, Vancouver, Canada, 9-11 May 2019. Link for preprint: https:// doi.org/10.1111/ijlh.13105. Link for abstract is presented in ISLH 2019. All authors have completed the ICMJE uniform disclosure form.

\section{Conflicts of Interest}

The authors declare that they have no conflicts of interest.

\section{Authors' Contributions}

Wardah Aslam, Maryam Habib conceptualized, designed, and conceived the presented research and contributed towards smooth collection of data, getting IRB approval, and getting institutional support. Wardah Aslam, Maryam Habib, and Saeeda Aziz participated in acquiring data and enrollment of patients in the study. Wardah Aslam, Maryam Habib, and Madiha Habib collected and assembled data. Maryam Habib and Madiha Habib helped in formulation of final data, analytical calculations, and interpretations of results. Wardah Aslam, Maryam Habib, Saeeda Aziz, and Madiha Habib wrote the article. All authors provided critical feedback, helped in manuscript writing, and formulating final version of research.

\section{References}

[1] N. Hwalla, A. Al Dhaheri, H. Radwan et al., "The prevalence of micronutrient deficiencies and inadequacies in the middle east and approaches to interventions," Nutrients, vol. 9, no. 3, p. 229, 2017.

[2] A. Lopez, P. Cacoub, I. C. Macdougall, and L. Peyrin-Biroulet, "Iron deficiency anaemia," The Lancet, vol. 387, no. 10021, pp. 907-916, 2016.

[3] S. Garzon, P. M. Cacciato, C. Certelli, C. Salvaggio, M. Magliarditi, and G. Rizzo, "Iron deficiency anemia in pregnancy: novel approaches for an old problem," Oman Medical Journal, vol. 35, no. 5, p. e166, 2020.

[4] S. Khatiwada, B. Gelal, N. Baral, and M. Lamsal, "Association between iron status and thyroid function in nepalese children," Thyroid Research, vol. 9, no. 1, p. 2, 2016.

[5] N. Shah, T. J. Ursani, N. A. Shah, and H. M. Z. Raza, "Prevalence and manifestations of hypothyroidism among population of Hyderabad, Sindh, Pakistan," Pure and Applied Biology, vol. 10, no. 3, pp. 668-675, 2021.

[6] T. Avni, A. Bieber, A. Grossman, H. Green, L. Leibovici, and A. Gafter-Gvili, "The safety of intravenous iron preparations," Mayo Clinic Proceedings, vol. 90, no. 1, pp. 12-23, 2015.

[7] M. Nairz, I. Theurl, D. Wolf, and G. Weiss, "Iron deficiency or anemia of inflammation?" Wiener Medizinische Wochenschrift, vol. 166, no. 13-14, pp. 411-423, 2016.

[8] N. N. Bashboosh, "Correlation between hypothyroidism and iron deficiency anemia IN female patients," World Journal of Pharmacy and Pharmaceutical Sciences, vol. 6, no. 7, pp. 80-89, 2017.

[9] A. T. Soliman, V. De Sanctis, M. Yassin, M. Wagdy, and N. Soliman, "Chronic anemia and thyroid function," Acta BioMedica: Atenei Parmensis, vol. 88, no. 1, pp. 119-127, 2017.
[10] S. N. Zehra, H. Ali, S. F. Fatima Zaidi, S. Kareem, A. Zahir, and M. Abid, "Iron deficiency anemia in patients with hypothyroidism, a single center, cross sectional study," The Professional Medical Journal, vol. 26, no. 10, pp. 1682-1687, 2019.

[11] C. M. Chaparro and P. S. Suchdev, "Anemia epidemiology, pathophysiology, and etiology in low- and middle-income countries," Annals of the New York Academy of Sciences, vol. 1450, no. 1, pp. 15-31, 2019.

[12] A. Dignass, K. Farrag, and J. Stein, "Limitations of serum ferritin in diagnosing iron deficiency in inflammatory conditions," International Journal of Chronic Diseases, vol. 2018, Article ID 9394060, 11 pages, 2018.

[13] M. H. Eftekhari, M. R. Eshraghian, H. Mozaffari-Khosravi, N. Saadat, and F. Shidfar, "Effect of iron repletion and correction of iron deficiency on thyroid function in iron-deficient Iranian adolescent girls," Pakistan Journal of Biological Sciences: PJBS, vol. 10, no. 2, pp. 255-260, 2007.

[14] M. M. El-Halabi, M. S. Green, C. Jones, and W. J. Salyers Jr, "Under-diagnosing and under-treating iron deficiency in hospitalized patients with gastrointestinal bleeding," World Journal of Gastrointestinal Pharmacology and Therapeutics, vol. 7, no. 1, pp. 139-144, 2016.

[15] S. Bouri and J. Martin, "Investigation of iron deficiency anaemia," Clinical Medicine, vol. 18, no. 3, pp. 242-244, 2018.

[16] K. Sehgal, U. Choksey, R. Dalal, D. Tina, and K. Shanaz, "Reference range evaluation of complete blood count parameters with emphasis on newer research parameters on the complete blood count analyzer sysmex XE-2100," Indian Journal of Pathology and Microbiology, vol. 56, no. 2, pp. 120-124, 2013.

[17] O. Ciepiela, A. Adamowicz-Salach, A. Radgowska, K. Żbikowska, and I. Kotuła, "Usefulness of reticulocyte parameters for diagnosis of hereditary spherocytosis in children," Indian Journal of Hematology and Blood Transfusion, vol. 33, no. 2, pp. 239-247, 2017.

[18] Y. Toki, K. Ikuta, M. Yamamoto et al., "Usefulness of reticulocyte hemoglobin equivalent for diagnosis of iron deficiency," Blood, vol. 128, no. 22, p. 3621, 2016.

[19] M. Wiciński, G. Liczner, K. Cadelski, T. Kołnierzak, M. Nowaczewska, and B. Malinowski, "Anemia of chronic diseases: wider diagnostics-better treatment?" Nutrients, vol. 12, no. 6, p. 1784, 2020.

[20] E. I. B. Peerschke, M. S. Pessin, and P. Maslak, "Using the hemoglobin content of reticulocytes (RET-He) to evaluate anemia in patients with cancer," American Journal of Clinical Pathology, vol. 142, no. 4, pp. 506-512, 2014.

[21] M. A. Uçar, M. Falay, S. Dağdas, F. Ceran, S. M. Urlu, and G. Özet, "The importance of RET-He in the diagnosis of iron deficiency and iron deficiency anemia and the evaluation of response to oral iron therapy," Journal of Medical Biochemistry, vol. 38, no. 4, pp. 496-502, 2019.

[22] R. Wirawan, A. T. Tedja, and F. Henrika, "Lydia AConcordance between reticulocyte hemoglobin equivalent and reticulocyte hemoglobin content in CKD patients undergoing hemodialysis," Acta Med Indones, vol. 49, p. 34, 2017.

[23] Y. Gelaw, B. Woldu, and M. Melku, "The role of reticulocyte hemoglobin content for diagnosis of iron deficiency and iron deficiency anemia, and monitoring of iron therapy: a literature review," Clinical Laboratory, vol. 65, 2019.

[24] P. Chinudomwong, A. Binyasing, R. Trongsakul, and K. Paisooksantivatana, "Diagnostic performance of reticulocyte hemoglobin equivalent in assessing the iron status," Journal of Clinical Laboratory Analysis, vol. 34, no. 6, Article ID e23225, 2020. 
[25] N. Khan, C. Altaf, H. Malik, Z. Sajjad, A. Khurshid, and M. Khadim, "Diagnostic accuracy of reticulocyte haemoglobin equivalent (rethe) in detecting iron deficiency anaemia keeping serum ferritin as gold standard," PAFMJ, vol. 69, no. 5, pp. 1010-1014, 2020.

[26] B. G. Singh, L. Duggal, N. Jain, V. Chaturvedi, J. Patel, and J. Kotwal, "Evaluation of reticulocyte hemoglobin for assessment of anemia in rheumatological disorders," International Journal of Rheumatic Diseases, vol. 22, no. 5, pp. 815-825, 2019.

[27] N. N. Dalimunthe and A. R. Lubis, "Usefulness of reticulocyte hemoglobin equivalent in management of regular hemodialysis patients with iron deficiency anemia," Romanian Journal of Internal Medicine, vol. 54, no. 1, pp. 31-36, 2016. 